\title{
Patterns of Tobacco Consumption among Indian Men with Schizophrenia Compared to Their Male Siblings
}

\author{
Saurabh Vatss', Harpreet Mehar', Triptish Bhatia', Jan Richard², Ruben C Gur², \\ Raquel E Gur ${ }^{2}$, Vishwajit L. Nimgaonkar ${ }^{3}$ and Smita N. Deshpande ${ }^{1 凶}$ \\ 1'Department of Psychiatry, PGIMER-Dr. Ram Manohar Lohia Hospital, New-Delhi, India \\ ${ }^{2}$ Department of Psychiatry, Neuropsychiatry Section, University of Pennsylvania, PA, USA \\ ${ }^{3}$ Departments of Psychiatry and Human Genetics, University of Pittsburgh, School of Medicine and Graduate School of Public Health, \\ Western Psychiatric Institute and Clinic, Pittsburgh, PA, USA
}

Objective Tobacco consumption among patients with schizophrenia has been investigated extensively in western countries, but there is a dearth of studies in India, where socio-economic and cultural variables are different. This study aims to investigate the patterns of tobacco consumption among schizophrenia patients compared with their non-psychotic siblings.

Methods Consenting, successive male outpatients diagnosed with schizophrenia ( $n=100$, DSM-IV criteria), and their non-psychotic brothers $(n=100)$ were compared. Following a structured diagnostic interview, detailed information about tobacco consumption (including smokeless tobacco) was obtained using the Fagerstrom Test for Nicotine Dependence for smoked tobacco, and FTND-smokeless tobacco. The University of Pennsylvania Computerized Neurocognitive battery (CNB) was administered to a sub-group of patients ( $\mathrm{n}=48$ ).

Results Schizophrenia patients initiated tobacco use at a significantly earlier age than their brothers, but there was no significant difference with regard to type, quantity or frequency of tobacco use (smoke or smokeless varieties). Patients who consumed tobacco had significantly higher positive symptom scores compared with non-users $(\mathrm{p}=0.043)$. There were no significant differences between nicotine dependent and non-dependent patients with regard to $\mathrm{CNB}$ domains except attention.

Conclusion Patterns of tobacco consumption were similar among schizophrenia patients and their non-psychotic brothers. Tobacco use was associated with increased positive symptom scores, but there were no significant differences in cognitive measures among nicotine dependent and non-dependent patients.

Psychiatry Investig 2012;9:245-251

Key Words Tobacco, Nicotine, Schizophrenia, Sibling, Familial, India.

\section{INTRODUCTION}

Several studies suggest that patients with schizophrenia (SZ) use tobacco more frequently than comparison groups, including patients with other psychiatric/medical disorders or healthy controls..$^{1-3}$ A meta-analysis of worldwide studies reported that schizophrenia patients smoked more frequently than the general population. ${ }^{4}$ Smoking among psychiatrically ill individuals may be initiated in response to environ-

Received: June 23, 2011 Revised: September 30, 2011

Accepted: May 10, 2012 Available online: September 6, 2012

$\triangle$ Correspondence: Smita N. Deshpande, MD

Department of Psychiatry, PGIMER-Dr. Ram Manohar Lohia Hospital, Park Street, New-Delhi 110001, India

Tel: +91-11-23404363, Fax: +91-11-23342122

E-mail: indusszgenes@gmail.com

(a) This is an Open Access article distributed under the terms of the Creative Commons Attribution Non-Commercial License (http://creativecommons.org/licenses/by$\mathrm{nc} / 3.0$ ) which permits unrestricted non-commercial use, distribution, and reproduction in any medium, provided the original work is properly cited. mental factors, but its maintenance may be related to psychopathology. ${ }^{5}$ The factors leading to tobacco abuse among SZ patients ${ }^{6,7}$ include social and cultural variables, ${ }^{8}$ as well as familial factors, ${ }^{9}$ with likely genetic susceptibility. ${ }^{10-15}$ Patients may also smoke as a form of self-medication, as nicotine administration enhances cognitive performance on a number of tasks. ${ }^{16}$ The "Psychological Tool" Model ${ }^{17}$ posits that the arousal state caused by tobacco consumption may improve attention and vigilance, leading to enhanced performance and increased psychological comfort that wanes with time, thus spurring smokers to consume tobacco regularly and repeatedly. Thus, smoking may be reinforced for several reasons. On the other hand, smoking abstinence can impair visuospatial working memory among patients with schizophrenia. ${ }^{18}$

The majority of studies describing tobacco use in SZ have been conducted in developed countries. Tobacco consumption is increasing rapidly in developing countries such as India. 
The average prevalence of tobacco use is $48 \%$ and $20 \%$, among Indian men and women respectively. ${ }^{19}$ Among Indians, an indigenous form of smoked tobacco called 'beedi' is preferred by $9 \%$ of adults and smokeless tobacco is preferred to smoked forms by approximately $20 \%$ of adults. About $5 \%$ use both smokeless and smoked forms. ${ }^{19}$ In India smoking is often prohibited by familial, cultural and religious practices e.g. less than $3 \%$ of Sikh men living in urban Delhi were found to be smokers compared to $45 \%$ of men. ${ }^{20}$ The Indian General Adult Tobacco Survey-GATS ${ }^{19}$ reported that in India tobacco use is inversely related to literacy level. Among Government employees $45 \%$ used tobacco while among self employed persons $49 \%$ used tobacco. Surprisingly $46.7 \%$ of unemployed persons used tobacco while only $7.6 \%$ of students used tobacco. ${ }^{19}$ In Delhi about $24.3 \%$ of general population used tobacco. ${ }^{19}$ Chandra et al. ${ }^{3}$ in their exploratory analyses revealed two profiles of smokers in India: the poorer, married, less welleducated beedi smoker from a rural background working as a casual laborer, and the less poor, educated, unmarried cigarette smoker from an urban background in professional or other occupation.

Average age of tobacco initiation in India is 17.8 years. ${ }^{19} \mathrm{An}$ other study by Neufeld et al. ${ }^{21}$ reported that regular smoking was greatest after the fifth decade (45-64 years) for men, with $63 \%$ reporting regular use. Reports of regular smoking among women peaked at $6.7 \%$ above 65 years of age. The greatest prevalence of chewing tobacco occurred for both genders in the seventh decade (60-69 years) with $35.0 \%$ (95\% CI: 34.136.0 ) of men and $19.6 \%$ (95\% CI: 18.8-20.4) of women in that age band reporting chewing tobacco use. ${ }^{21}$

There is limited research regarding tobacco use among Indians with SZ. ${ }^{8,3,22-24}$ The most systematic study to date ${ }^{8}$ reported that among 286 urban male outpatients with schizophrenia, $38 \%$ were current smokers as compared to $22.8 \%$ among patients with Non Psychotic Disorders, 23.8\% with mood disorders and $40 \%$ with medical illnesses. Since tobacco use was lower among schizophrenia patients, which they attributed to socio-economic factors, they noted that studies could provide novel clues about the risk for tobacco use in SZ.

The present study examined the prevalence of smoke and smokeless tobacco consumption in a sample of male patients with schizophrenia. The study focused on men, as current daily tobacco consumption is estimated at $23.6 \%$ among men and less than 5\% in women in Delhi, where this study was conducted. ${ }^{19}$ Several socio-cultural and socioeconomic factors could influence smoking behavior. ${ }^{25}$ We compared the SZ patients with non-psychotic sibling controls. Siblings form an excellent comparison group as they share many environmental factors, such as cultural and socio-economic background that may confound analyses of tobacco consumption.
Other factors such as socioeconomic differences, degree of tobacco use, cognitive differences were examined.

\section{METHODS}

\section{Site}

The study was conducted at the Post Graduate Institute of Medical Education and Research-Dr. Ram Manohar Lohia Hospital (PGIMER-Dr. RMLH), New Delhi. PGIMER-Dr. RMLH is a 1200 bed, tertiary care hospital that treats patients primarily from the Delhi metropolitan area, as well as all other regions of India.

\section{Sample}

The cases comprised successive, consenting adults, clinically diagnosed with SZ who presented at the psychiatry outpatient department (OPD) at Dr. R.M.L. Hospital. All participants were between 18 to 60 years of age. Availability of a consenting, non-psychotic male sibling was another inclusion criterion. Patients diagnosed with other co-morbid psychiatric or neurological disorders that could confound the diagnosis of SZ, were excluded. The comparison group consisted of consenting brothers of the SZ patients, nearest in age to the probands who were not diagnosed with any psychiatric or neurological disorder.

\section{Clinical and diagnostic assessments}

All clinical assessments were conducted by one investigator (SV). Structured clinical interviews were conducted using the Diagnostic Interview for Genetic Studies (DIGS, Hindi version) ${ }^{26,27}$ This information was supplemented by interviews with relatives and available medical records. DIGS was administered to healthy siblings also, to rule out any psychiatric illness. The Fagerstrom Test for Nicotine Dependence (FTND) was used to assess tobacco use and nicotine dependence. ${ }^{28}$ The FTND is a self-rated six-item instrument. For smokeless tobacco, the FTND-smokeless tobacco (FTND-ST) was used. ${ }^{29}$ The FTND was supplemented with a semi-structured questionnaire in Hindi designed to assess the type, quantity and frequency of smokeless tobacco. Details regarding the status of tobacco consumption, age of initiation, type and amount of tobacco consumed were thus obtained. Associated medical comorbidity was also assessed.

Cognitive assessment was carried out on the Penn's Computerized Neurocognitive battery (CNB) which includes measures that distinguish $\mathrm{SZ}$ cases and relatives from controls. ${ }^{30}$ Accuracy and response time were recorded for each of the cognitive domains. The Hindi version of the CNB was used to assess: Abstraction and mental flexibility, Attention, Face memory, Spatial memory, Working memory, Spatial ability, Sen- 
sorimotor, Emotion Processing.

\section{Consensus diagnosis}

Each participant's clinical information was discussed in detail by the interviewer (SV) who had assessed the participant, with board certified psychiatrists/psychologists. Consensus diagnoses were assigned in consultation with them.

Written informed consent was obtained from all participants. Study approval was obtained from the Institutional Ethics Committee at PGIMER-DRMLH and the Institutional Review Board at the University of Pittsburgh.

\section{Statistical analysis}

We compared categorical variables using the Chi square test. The Student's t-test was used to compare continuous variables. The CNB scores were compared between tobacco dependents and non-dependents using Mann Whitney U-test. The Statistical Package for Social Sciences (SPSS version 17.0.2, 2008) was used for all analyses.

\section{Power analysis}

The sample size for the study was based on published literature in India. The prevalence of tobacco consumption in Indian patients with SZ is estimated at $40 \%$ from Srinivasan study. ${ }^{8}$ Assuming $\alpha=0.05,25 \%$ error in precision, the following formula provided a sample estimate of $96 \mathrm{SZ}$ patients and 96 siblings:
$2 \times \sqrt{\mathrm{p} \mathrm{q} / \mathrm{n}=\text { prevalence }} \times$ error in precision $/ 100$

( $p=$ Prevalence, $q=100$-prevalence, $n=$ number of subjects)

\section{RESULTS}

There was no significant difference in the mean age or level of education among the SZ patients compared with their brothers (Table 1). Significantly more SZ participants were single or separated $(\mathrm{p}=0.04)$. SZ participants were also more likely to be unemployed $(\mathrm{p}=0.0001)$ and less likely to be living independently $(\mathrm{p}=0.0001)$. Modified mini mental state examination (MMSE) scores of the brothers were significantly higher than the SZ patients $(t=65.643, p<0.001)$. Sociocultural factors were compared between schizophrenia subjects and their male siblings. Most subjects were Hindus (84\%), followed by Muslims (11\%), Sikh (4\%) and Christian (1\%). Three fourths (77\%) subjects depended on family members or relatives for housing where as brothers resided independently on their own $(54 \%)(p<0.001)$.Unemployment was more prevalent in subjects with schizophrenia (54\%) while majority of their brothers $(86 \%)$ were employed now and in the past. The difference was highly significant $(\mathrm{p}<0.001)$ (Table 3 ).

The proportion of SZ patients who had consumed tobacco in the past, or were currently consuming tobacco did not differ significantly from their siblings (Table 1). We compared current tobacco users between brothers and patients using chi-square. Patients with schizophrenia showed a lower rate (trend) than their brothers (Chi-square $=3.5, \mathrm{p}=0.06$ ).

Table 1. Socio-demographic characteristics and prevalence of tobacco use

\begin{tabular}{|c|c|c|c|c|c|}
\hline Variables $($ mean $\pm S D)$ & $\begin{array}{c}\text { Patients with } \\
\text { schizophrenia }(\mathrm{N}=100)\end{array}$ & $\begin{array}{l}\text { Brothers } \\
(\mathrm{N}=100)\end{array}$ & $\chi^{2}$ & $\mathrm{df}$ & $\mathrm{p}$ value \\
\hline Age (years) & $30.96( \pm 7.76)$ & $30.74( \pm 7.5)$ & 3.36 & 3 & 0.339 \\
\hline Marital status married/Single* & $46 / 54$ & $60 / 40$ & 6.31 & 1 & 0.043 \\
\hline \multicolumn{6}{|l|}{ Education } \\
\hline In years & $9.34 \pm 4.05$ & $10.03 \pm 3.8$ & $\mathrm{t}=1.24$ & & 0.216 \\
\hline \multicolumn{6}{|l|}{ Occupational } \\
\hline $\begin{array}{l}\text { Status: never employed/currently unemployed/ } \\
\text { employed/student }\end{array}$ & 06/48/39/07 & 02/01/86/11 & 65.64 & 3 & $<0.001$ \\
\hline \multicolumn{6}{|l|}{ Living } \\
\hline Arrangement: independent/dependent & 23/77 & $54 / 46$ & 20.29 & 1 & $<0.001$ \\
\hline MMSE & $23.62 \pm 5.3$ & $28.88 \pm 3.82$ & -8.05 & & $<0.001$ \\
\hline Tobacco use: current/past/never & $34 / 14 / 52$ & $47 / 08 / 45$ & 4.23 & 2 & 0.121 \\
\hline
\end{tabular}

*'Single' includes unmarried/divorced/separated/widowed. df: degrees of freedom, MMSE: Mini mental state examination

Table 2. Characteristics of current tobacco users

\begin{tabular}{|c|c|c|c|c|}
\hline & Patients with Schizophrenia $(\mathrm{N}=34)$ & Brothers $(\mathrm{N}=47)$ & $\mathrm{t}$ & $\mathrm{p}$ value \\
\hline Fagerstrom Score (Smoked form, mean \pm SD) & $5.85 \pm 2.28$ & $4.8 \pm 2.18$ & -11.047 & 0.07 \\
\hline Fagerstrom Score for Smokeless: mean \pm SD & $9.85 \pm 3.53$ & $9.29 \pm 2.6$ & 0.571 & NS \\
\hline Age of starting Tobacco: mean \pm SD & $22.79 \pm 4.69$ & $24.44 \pm 3.58$ & 2.013 & 0.047 \\
\hline
\end{tabular}


Table 3. Comparison of patients \& brothers who ever or never used tobacco

\begin{tabular}{|c|c|c|c|c|c|c|}
\hline Variables & $\begin{array}{l}\text { Tobacco user } \\
\text { (patient) } \\
(\mathrm{N}=48)\end{array}$ & $\begin{array}{c}\text { Non users } \\
\text { (patient) } \\
(\mathrm{N}=52)\end{array}$ & $\begin{array}{l}\chi^{2} / t, d f \\
\text { p-value }\end{array}$ & $\begin{array}{l}\text { Tobacco user } \\
\text { (brother) } \\
(\mathrm{N}=55)\end{array}$ & $\begin{array}{c}\text { Non users } \\
\text { (brother) } \\
(\mathrm{N}=45)\end{array}$ & $\begin{array}{l}\chi^{2} / t, d f \\
\text { p-value }\end{array}$ \\
\hline Age in years & & & $0.150,98,0.876$ & & & $-1.570,98,0.120$ \\
\hline Mean \pm SD & $30.83 \pm 7.35$ & $31.08 \pm 8.19$ & & $31.80 \pm 7.21$ & $29.44 \pm 7.75$ & \\
\hline Marital status & & & $6.957,2,0.031$ & & & $8.53,2,0.014$ \\
\hline Married & $19(39.6 \%)$ & $27(51.9 \%)$ & & $40(72.7 \%)$ & $20(44.4 \%)$ & \\
\hline Unmarried & $19(39.6 \%)$ & $23(44.2 \%)$ & & $14(25.4 \%)$ & $22(48.9 \%)$ & \\
\hline Divorced or separated or widow & $10(20.8 \%)$ & $2(0.38 \%)$ & & $1(1.8 \%)$ & $3(6.67 \%)$ & \\
\hline Education in years & & & $4.18,5,0.523$ & & & $11.83,5,0.037$ \\
\hline Illiterate & $1(2.08 \%)$ & $3(5.76 \%)$ & & $5(9.1 \%)$ & 0 & \\
\hline$<5$ & $7(14.6 \%)$ & $9(17.3 \%)$ & & $3(5.4 \%)$ & $2(4.4 \%)$ & \\
\hline $5-10$ & $22(45.8 \%)$ & $22(42.3 \%)$ & & $30(54.5 \%)$ & $17(37.8 \%)$ & \\
\hline 12 & $14(29.1 \%)$ & $9(17.3 \%)$ & & $12(21.8 \%)$ & $14(31.1 \%)$ & \\
\hline Graduate & $3(6.25 \%)$ & $6(11.5 \%)$ & & $3(9.1 \%)$ & $10(22.2 \%)$ & \\
\hline Professional & $1(2.08 \%)$ & $3(5.76 \%)$ & & $2(3.6 \%)$ & $2(4.4 \%)$ & \\
\hline Mean \pm SD & $9.46 \pm 3.65$ & $9.23 \pm 4.41$ & & $8.93(4.01)$ & $11.38(3.08)$ & \\
\hline Occupational status & & & $2.511,2,0.285$ & & & $15.809,3,<0.001$ \\
\hline Never employed & $1(2.08 \%)$ & $5(9.61 \%)$ & & $1(1.8 \%)$ & $1(2.2 \%)$ & \\
\hline Currently unemployed & $24(50 \%)$ & $24(46.1 \%)$ & & $1(1.8 \%)$ & $33(73.3 \%)$ & \\
\hline Employed & $23(47.9 \%)$ & $23(44.2 \%)$ & & $53(96.3 \%)$ & $11(24.4 \%)$ & \\
\hline Living arrangement & & & $0.869,1,0.351$ & & & $3.00,1,0.083$ \\
\hline Independent & $13(27.1 \%)$ & $10(19.2 \%)$ & & $34(61.8 \%)$ & $20(44.4 \%)$ & \\
\hline Dependent & $35(72.9 \%)$ & $42(80.8 \%)$ & & $21(38.1 \%)$ & $25(55.5 \%)$ & \\
\hline Mean age of onset of illness & $26.21 \pm 6.63$ & $24.98 \pm 6.78$ & $-0.914,98,0.363$ & - & - & - \\
\hline Mean duration of illness & $4.63 \pm 4.1$ & $6.10 \pm 5.0$ & $1.588,98,0.116$ & - & - & - \\
\hline SAPS & $22.54 \pm 11.24$ & $15.08 \pm 9.97$ & $-3.519,<0.001$ & - & - & - \\
\hline SANS & $49.35 \pm 16.2$ & $52.25 \pm 15.5$ & 0.913 & - & - & - \\
\hline MMMSE & $22.40 \pm 5.0$ & $24.75 \pm 5.32$ & 2.265 & - & - & - \\
\hline
\end{tabular}

Values for continuous variables are shown as mean \pm standard deviation. SAPS: Scale for Assessment for Positive Symptoms, SANS: Scale for Assessment for Negative Symptoms, MMMSE: Modified Mini Mental Status Examination

There was no significant difference on age and education between current users and non users in the pooled data ( $t$ test). Among current users there was no significant difference between patients and brothers on marital status. All except one brother were employed while $50 \%$ of patients were employed. There was no significant difference between current user patients and their brothers on age and education. There was no significant difference between patients and their brothers on living arrangement among current smokers which suggests that living arrangement was not associated with smoking status. In addition almost all current smoker brothers were employed but $50 \%$ of patients were unemployed which suggests that smoking was not related to socioeconomic status. It may be a possibility that those patients who stayed with parents might get money for smoking from parents.

The Fagerstrom scores for smoked or smokeless forms of tobacco were similar among SZ patients and their siblings who currently used nicotine, though the age at initiation of tobacco use was significantly earlier among SZ patients $(22.79 \pm 4.69$ years vs. $24.44 \pm 3.58$ years; $\mathrm{t}=2.013, \mathrm{p}<0.001$ )(Table 2 ). There were 34 current users among the SZ patients and 47 among their brothers. The majority of patients and their brothers smoked tobacco (56.2\% vs. 50.9\%); fewer used smokeless forms ( $20.8 \%$ vs. $23.6 \%$, respectively). Some consumed tobacco in both forms (22.9\% of SZ patients and $25.4 \%$ of the siblings). Among SZ patients, 13 out of 28 smokers (46.4\%) while among their brothers, 12/35 smokers (34.2\%) were dependent on nicotine by DSM IV criteria, but the difference was not statistically significant. Among SZ smokeless tobacco users, 7 out of 13 (53.84\%) were dependent, whereas 14 out of 28 brothers were dependent (not statistically significant).

We compared SZ patients who had never used tobacco, with those who had consumed tobacco in the past or were currently using it (Table 3). The mean Scale for Assessment for Posi- 


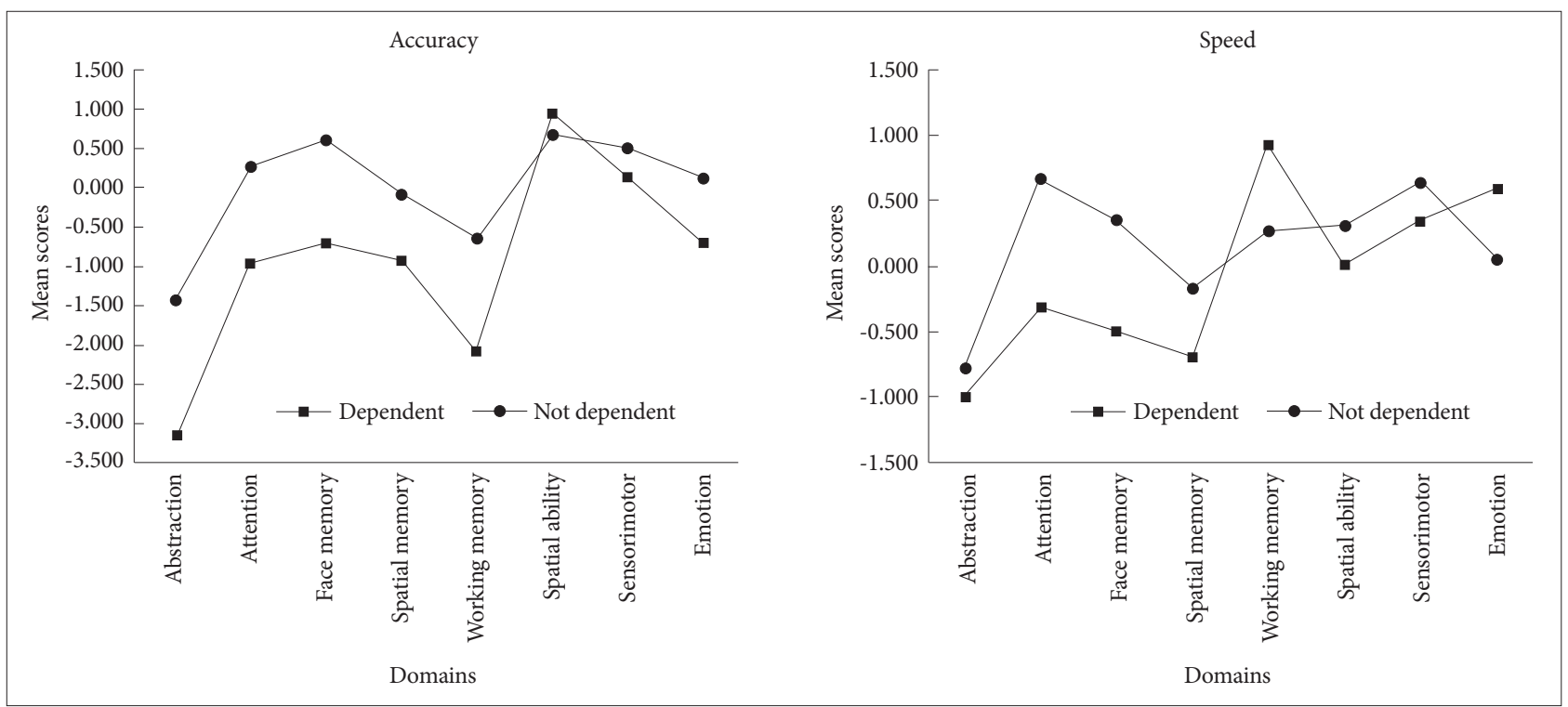

Figure 1. Cognitive domains assessed using the Penn CNB among patients. CNB: Penn's Computerized Neurocognitive Battery.

tive Symptoms scores of SZ patients who ever used tobacco were significantly higher than among non-users $(\mathrm{t}=-3.519, \mathrm{p}<$ 0.001)(Table 3). There was no significant difference between users and non-users with regard to Scale for Assessment for Negative Symptoms scores, age at onset of SZ or duration of illness. Mean modified MMSE scores were significantly lower among tobacco users than among non-tobacco using patients (mean \pm SD: $22.40 \pm 5.04$ vs. $24.75 \pm 5.32, \mathrm{p}=0.026$ ). Among patients who completed the CNB $(n=48)$, there were 19 tobacco users based on FTND scores (nicotine dependent, $n=13$ ). When nicotine dependent patients were compared with non-dependent patients with regard to CNB data, the former scored significantly worse than the latter with regard to accuracy and efficiency indices for attention $(Z=-3.092, p=0.001$ and $\mathrm{Z}=-2.84, \mathrm{p}=0.003$, respectively, Figure 1 ). Since there was significant difference on SAPS between tobacco users and non users we adjusted CNB scores with total SAPS scores. Tobacco users were significantly worse than non users on working memory speed $(\mathrm{Z}=-2.147, \mathrm{p}=0.032)$. There were no significant differences with regard to the other cognitive domains.

We also compared siblings who had ever used nicotine with those who never used it. Most of the brothers in the non-user group were aged less than 30 years (53\%), were students (24.4\%) and most of them were dependent on family support (55.5\%). The mean years of education among tobacco using siblings was significantly lower than non-users $(8.93 \pm 4.01$ vs. $11.38 \pm 3.08, t=3.36, p=0.001)$. Most of the brothers were employed, but overall employment rates were higher among the tobacco using brothers ( $96.3 \%$ vs. $73.3 \%)$. SZ patients were more likely to be dependent (77\%) on relatives for residence, food and other basic needs in comparison to brothers (46\%) who were mostly self-supported $\left(\chi^{2}=20.294, p<0.001\right.$, df 1$)$.

\section{DISCUSSION}

We report on the prevalence of smoked and smokeless tobacco use among Indian SZ patients and their non-psychotic siblings. Though the patients initiated tobacco use earlier than their siblings, at the time of evaluation the patterns of usage were similar. Our results are consistent with an earlier report from India. ${ }^{8}$ In the present study, the prevalence of tobacco use among SZ patients (48\%) and their siblings (55\%) was comparable to the average rate for the Indian male population $(57 \%)^{31}(47.9 \%){ }^{19}$ The results from an earlier Indian study of SZ patients and our study are dissimilar to several studies from developed countries, which reported two to threefold higher rates of consumption among SZ patients compared with the general population in those countries ${ }^{7,32} \mathrm{In}$ deed, one study in the U.S. reported a prevalence rate of $90 \%$ among SZ patients ${ }^{33}$ while others reported it as $61 \% .^{34}$ The reasons for these differences are unclear, but may provide novel clues about the high prevalence rates of nicotine use among SZ patients in developed countries.

We selected siblings as a comparison group for our study, because they have some features that increase their suitability in comparison with community based controls. In India, siblings typically live together well into adulthood. Thus, apart from shared genetic factors, they have a substantial proportion of shared environmental factors. The brothers and the patients had very similar ages and educational backgrounds. While tobacco use began earlier among patients, continuation was commoner among brothers. In the present study, 33.7\% 
subjects with schizophrenia and $49 \%$ brothers who currently used tobacco, consumed smokeless tobacco either exclusively or in combination with smoked. Among those who consumed smokeless tobacco, $50 \%$ in both the groups were highly dependent with FTND score $>8$. A prior U.S. study reported that non-psychotic siblings of patients with schizophrenia reported a higher prevalence of substance consumption including tobacco than that of general population. ${ }^{9}$ Others have speculated that nicotine addiction may indicate susceptibility to schizophrenia. ${ }^{15}$

Tobacco use significantly predated the onset of SZ by 3-4 years (22.79 vs. 26 years), consistent with previous studies. ${ }^{7,35,36}$ In the present study, the mean age at onset of illness was similar between tobacco users and non-user patients, in agreement with Beratis study. ${ }^{36}$ We also compared selected aspects of psychopathology among SZ smokers and non- smokers, though the inability to account for medications and duration of treatment limit the informativeness of such comparisons. The mean SAPS scores were significantly higher among tobacco user patients, in agreement with previous studies. ${ }^{37,38}$ There was no significant difference between tobacco users and nonusers on SANS scores in our sample, though prior studies reported significantly lower SANS score in tobacco users. ${ }^{36-38}$ In our sample, all SZ patients had impaired global functioning (GAF score below 40). Thus, tobacco-using patients fared worse than non-users with regard to several clinical variables, not supporting the notion that tobacco use may reflect a form of self-medication in $\mathrm{SZ}^{39}$

We also explored cognitive function among the SZ patients. Mean modified MMSE scores were significantly lower among tobacco users. In a smaller sample of patients $(n=48)$ to whom the $\mathrm{CNB}$ was administered, there was no significant difference between tobacco users and non-users. On the other hand, tobacco dependent patients fared better on attention domains (accuracy and efficiency) than non-dependent patients. Our results are consistent with prior studies reporting that the arousal state caused by tobacco consumption may improve attention and vigilance leading to enhanced performance initially that wanes off after some time, and motivates the user to continuously consume tobacco. ${ }^{17}$

Some additional limitations of this study should be noted. Variables such as treatment status were not considered in the analyses, as available data and compliance with medications were uncertain and this was a cross sectional study. No female subjects were included as tobacco use is much lower among Indian women than men. The $\mathrm{CNB}$ evaluations were unavailable for all patients, limiting the interpretations. While a second group of unrelated controls would have provided additional information, their inclusion would significantly have increased costs and would have impacted feasibility.
In conclusion, Indian SZ patients initiated tobacco use earlier than their unaffected siblings. At the time of evaluation, however, the patterns of use were very similar. Among the patients, tobacco use was associated with elevated SAPS scores and lower MMSE scores compared with non-users, but it is difficult to draw causal conclusions as confounding factors like treatment status could not be considered. In the same vein, marginally improved performance in some cognitive domains among tobacco dependent patients needs to be interpreted with caution. The prevalence of tobacco consumption in our study was relatively low when compared to the prevalence of tobacco use among patients with schizophrenia in economically developed countries. Cross-cultural studies of tobacco consumption may provide novel insights about novel protective or risk factors for tobacco consumption.

\section{Acknowledgments}

We thank our research participants and research colleagues. This work was supported in part by grants from NIH, \#MH084856 to REG and RCG and MH63480 and D43 TW 06167 to VLN.

\section{REFERENCES}

1. Buckley PF. Substance abuse in schizophrenia: a review. J Clin Psychiatry 1998;59(Suppl 3):26-30.

2. Punnoose S, Belgamwar MR. Nicotine for schizophrenia. Cochrane Database Syst Rev 2006:CD004838.

3. Chandra PS, Carey MP, Carey KB, Jairam KR, Girish NS, Rudresh HP. Prevalence and correlates of tobacco use and nicotine dependence among psychiatric patients in India. Addict Behav 2005;30:1290-1299.

4. de Leon J, Diaz FJ. A meta-analysis of worldwide studies demonstrates an association between schizophrenia and tobacco smoking behaviors. Schizophr Res 2005;76:135-157.

5. Chiles J, Cohen S, Maiuro R, Wright R. Smoking and schizophrenic psychopathology. Am J Addict 1993;2:315-319.

6. McCreadie RG, Kelly C. Patients with schizophrenia who smoke. Private disaster, public resource. Br J Psychiatry 2000;176:109.

7. Kelly C, McCreadie RG. Smoking habits, current symptoms, and premorbid characteristics of schizophrenic patients in Nithsdale, Scotland. Am J Psychiatry 1999;156:1751-1757.

8. Srinivasan TN, Thara R. Smoking in schizophrenia -- all is not biological. Schizophr Res 2002;56:67-74.

9. Smith MJ, Barch DM, Wolf TJ, Mamah D, Csernansky JG. Elevated rates of substance use disorders in non-psychotic siblings of individuals with schizophrenia. Schizophr Res 2008;106 294-299.

10. Bierut LJ, Madden PA, Breslau N, Johnson EO, Hatsukami D, Pomerleau OF, et al. Novel genes identified in a high-density genome wide association study for nicotine dependence. Hum Mol Genet 2007;16: 24-35.

11. Saccone SF, Hinrichs AL, Saccone NL, Chase GA, Konvicka K, Madden $\mathrm{PA}$, et al. Cholinergic nicotinic receptor genes implicated in a nicotine dependence association study targeting 348 candidate genes with 3713 SNPs. Hum Mol Genet 2007;16:36-49.

12. Owen MJ, Williams NM, O'Donovan MC. The molecular genetics of schizophrenia: new findings promise new insights. Mol Psychiatry 2004; 9:14-27.

13. Badner JA, Gershon ES. Meta-analysis of whole-genome linkage scans of bipolar disorder and schizophrenia. Mol Psychiatry 2002;7:405-411.

14. Lewis CM, Levinson DF, Wise LH, DeLisi LE, Straub RE, Hovatta I, et al. Genome scan meta-analysis of schizophrenia and bipolar disorder, 
part II: Schizophrenia. Am J Hum Genet 2003;73:34-48.

15. de Leon J. Smoking and vulnerability for schizophrenia. Schizophr Bull 1996;22:405-409.

16. Lavin M, Siris S, Mason S. What is the clinical importance of cigarette smoking in schizophrenia? Am J Addict 1996;5:189-208.

17. Ashton H, Stepney R. Smoking Psychology and Pharmacology. New York: Tavistock; 1982.

18. Levin ED, Simon BB. Nicotinic acetylcholine involvement in cognitive function in animals. Psychopharmacology (Berl) 1998;138:217-230.

19. GATS. Global Adult Tobacco Survey; 2009-2010.

20. Venkatraman S, Mukhopadhya A, Muliyil J. Trends of smoking in medical students. Indian J Med Res 1996;104:316-320.

21. Neufeld KJ, Peters DH, Rani M, Bonu S, Brooner RK. Regular use of alcohol and tobacco in India and its association with age, gender, and poverty. Drug Alcohol Depend 2005;77:283-291.

22. Saddichha S, Rekha DP, Patil BK, Murthy P, Benegal V, Isaac MK. Knowledge, attitude and practices of Indian dental surgeons towards tobacco control: advances towards prevention. Asian Pac J Cancer Prev 2010;11:939-942.

23. Saddichha S, Khess CR. Prevalence of tobacco use among young adult males in India: a community-based epidemiological study. Am J Drug Alcohol Abuse 2010;36:73-77.

24. Shidhaye R, Patel V. Association of socio-economic, gender and health factors with common mental disorders in women: a population-based study of 5703 married rural women in India. Int J Epidemiol 2010;39: 1510-1521.

25. Firoz A. Smoking in patients with mental disorders: observations in a developing country. ORION Med J 2003;16:106-108.

26. Nurnberger JI Jr, Blehar MC, Kaufmann CA, York-Cooler C, Simpson SG, Harkavy-Friedman J, et al. Diagnostic interview for genetic studies. Rationale, unique features, and training. NIMH Genetics Initiative. Arch Gen Psychiatry 1994;51:849-859.

27. Deshpande SN, Mathur MN, Das SK, Bhatia T, Sharma S, Nimgaonkar
VL. A Hindi version of the Diagnostic Interview for Genetic Studies. Schizophr Bull 1998;24:489-493.

28. Heatherton TF, Kozlowski LT, Frecker RC, Fagerstrom KO. The Fagerstrom Test for Nicotine Dependence: a revision of the Fagerstrom Tolerance Questionnaire. Br J Addict 1991;86:1119-1127.

29. Ebbert JO, Patten CA, Schroeder DR. The Fagerstrom Test for Nicotine Dependence-Smokeless Tobacco (FTND-ST). Addict Behav 2006; 31:1716-1721.

30. Gur RC, Ragland JD, Moberg PJ, Bilker WB, Kohler C, Siegel SJ, et al. Computerized neurocognitive scanning: II. The profile of schizophrenia. Neuropsychopharmacology 2001;25:777-788.

31. NFHS-3. National Family Health Survey, India; 2005-2006.

32. Smith M, Barch DM, Wolf TJ, Mamah D, Csernansky JG. Elevated rates of substance use disorders in non-psychotic siblings of individuals with schizophrenia. Schizophr Res 2008;106:294-299.

33. Williams J, Ziedonis D. Addressing tobacco among individuals with a mental illness or an addiction. Addict Behav 2004;29:1067-1083.

34. Himelhoch S, Daumit G. To whom do psychiatrists offer smokingcessation counseling? Am J Psychiatry 2003;160:2228-2230.

35. Gurpegui M, Martinez-Ortega JM, Aguilar MC, Diaz FJ, Quintana HM, de Leon J. Smoking initiation and schizophrenia: a replication study in a Spanish sample. Schizophr Res 2005;76:113-118.

36. Beratis S, Katrivanou A, Gourzis P. Factors affecting smoking in schizophrenia. Compr Psychiatry 2001;42:393-402.

37. Ziedonis DM, Kosten TR, Glazer WM, Frances RJ. Nicotine dependence and schizophrenia. Hosp Community Psychiatry 1994;45:204-206.

38. Patkar AA, Gopalakrishnan R, Lundy A, Leone FT, Certa KM, Weinstein SP. Relationship between tobacco smoking and positive and negative symptoms in schizophrenia. J Nerv Ment Dis 2002;190:604-610.

39. Nisell M, Homikos GG, Svensson TH. Nicotine dependence, midbrain dopamine systems and psychiatric disorders. Pharmacol Toxicol 1995; $76: 157-162$ 